\title{
THE USE OF THE PARTIAL LEAST SQUARES REGRESSION PROCEDURE TO PREDICT THE NET PROFIT IN PRODUCTION OF EGG-TYPE PULLETS
}

\author{
Y.A. Abdel-Aziz ${ }^{1}$, H.B.A. Gharib ${ }^{2}$ and M.A. Ibrahim ${ }^{2}$
}

1- Animal Production Research Institute (APRI), Ministry of Agriculture, Giza, Egypt, 2- Department of Animal production, Faculty of Agriculture, Cairo University, Giza, Egypt

\section{SUMMARY}

Data on the financial variables of 43 cycles of Lohman Brown commercial eggtype pullets production were collected for 15 years (1990-2005) from Al-Nahda farm at Nubaria region in the north western part of Egypt. The flock size per cycle ranged between 25700 to 79500 birds, with a mean of 39600 birds, during the data collection period.

The data were analyzed by the Partial Least Squares Regression (PLS) procedure using the XLSTAT 1.01, 2009 software. The objective of the study was to find out the possibility of projecting the net profit per-cycle (NP) as a dependent (response) variable from information on five independent (explanatory) cost variables. The cost variables included feed cost (FC), purchased chicks price (CP), veterinary cost (VC), cost of depreciation of the buildings and equipment (DC), and other cost (OC). These five variables were assembled in a principal component which was used in building the projection model (equation).

Mean NP was L.E 62973, and the highest cost variable was FC (L.E 156182) representing about $46 \%$ of the total cost. The correlation matrix between all variables showed significant correlation coefficients $(P<0.05)$ between the independent variables and between each of them and the dependent variable (NP).

The model quality index showed high explanatory power of the generated component for NP. An equation for the projection model of NP was built, and the goodness of fit statistics for NP showed high accuracy $\left(R^{2}=0.90\right)$. The model can be used for prediction and simulation purposes.

Keywords: Egg-type pullets, partial least squares (PLS) regression procedure, projection of net profit

\section{INTRODUCTION}

The production of ready-to-lay pullets represents one of the good investment opportunities in the poultry business. This is particularly suited to the producers who have mastered the growing of chicks from the day they are hatched up to the time they are about to lay. These pullets are 100-days old female egg-type birds which are preferred by some producers over the day-old chicks.

There is a demand for pullets because many producers want birds that produce cash flow almost immediately by the time they receive the birds. By this time, the

Issued by The Egyptian Society of Animal Production 
birds are already vaccinated against major diseases and are no longer as delicate to be taken care of as the young chicks (Hofstad et al., 1984). In other words, the risk is much less in this type of operations.

Egg-type pullets' production has been managed successfully under a wide range of feeding quality and disease challenge situations. The goal of the brooding and grow-up systems of production is to provide pullets of ideal weight, condition, and stage of sexual maturity as they enter the laying house. It is production inputs which make the variation between birds; performance, and consequently profit.

Cost of production and returns are the major concerns in poultry production, provided other production parameters are within the normal range as suggested for good performance (Farooq et al., 2002). Cost items, in particular, determine to a considerable extent the net profit per cycle.

The present work is, therefore, an effort to study the cost variables which have major effects on the net profit per cycle in an egg-type replacement pullets farm. Also, to find out the possibility of predicting the net profit from such variables. The partial least squares (PLS) regression procedure was applied to determine the variable importance for projection (VIP), and the principal components which can be used in constructing an equation for projection of the net profit per cycle.

\section{MATERIAL AND METHODS}

\section{Source of Data:}

Data on 43 cycles of egg-type Lohman Brown pullets production during the period from 1990-2005 were collected from the egg production project at Noubaria in the north eastern region of Egypt. This project belongs to the Central Fund for livestock development in the reclaimed land (CFLD). The project was established in (1986) to provide small farmers with a good source of egg-type pullets at the age of 100 days. The flock size per cycle ranged between 25700 to 79500 birds, with a mean of 39600 birds, during the data collection period.

At the end of each cycle the 100-day old pullets were sold at market price, and cash values of cost and revenue items were recorded. The net profit was calculated, defined as the difference between the total revenues and the total costs. All variables are expressed in Egyptian Pounds (L.E).

The data were pertaining to the price of the purchased day-old chicks (CP), feed cost (FC), veterinary cost (VC), depreciation cost of buildings and equipment (DC), and other cost of production (OC). The other cost included fuel, water and electricity, maintenance, rent of land, and miscellaneous expenses.

\section{Flock Management:}

Lohman Brown chicks were raised in a closed house with pad-cooling system from one day until 100 days of age. Chicks were placed in wire cages (100 cm width by $50 \mathrm{~cm}$ depth and $40 \mathrm{~cm}$ height) at 14 chicks per cage, with two water nipples and automatic chain feeder. Chicks received continuous illumination during the first two days post-hatch, and were transferred gradually to 8-hr photoperiod daily at 14 days of age, and this continues until 100 days of age. The average of light intensity was about $10 \mathrm{~lx}$.

Brooding temperature of $33{ }^{\circ} \mathrm{C}$ was maintained for the first three days then decreased to $30{ }^{\mathrm{O}} \mathrm{C}$ for the rest of the first week. The temperature was reduced 
gradually to $22{ }^{\circ} \mathrm{C}$ by the end of the second week until the fourth week. From the beginning of the fifth week to the end of the cycle when chicks reach 100 days of age, the birds were exposed to $22{ }^{\circ} \mathrm{C}$. Electric fan heaters were used to provide and maintain the required temperature. Relative humidity was set at 50-60\%.

Feed and water were available ad libitum to meet the requirements set by the National Research Council (NRC, 1994). The birds were subjected to vaccination program according to that outlined by Hofstad et al. (1984). The cycles continue all over the year with two - four weeks elapsing between every two consecutive cycles to allow for taking sanitary measures. The produced 100-day old pullets were sold to the farmers at market price.

\section{Statistical analysis:}

The Partial Least Squares (PLS) regression procedure as in XLSTAT (2009).1.01 software was applied to the data. The data included one dependent (response) variable, net profit (NP), and five independent (explanatory) variables: feed cost (FC), chick price (CP), veterinary cost (VC), depreciation cost (DP), and other cost (OC).

After selecting the variables which are relevant to NP, the analysis proceeded for seven steps to end up with a prediction equation for NP: 1) computing the basic statistics (means, standard deviations and minimum and maximum values), 2) constructing the correlation matrix among variables, 3) testing the model quality by number of components, 4) estimating model parameters, 5) testing goodness of fit for the dependent variable (NP),6) identifying the variable importance in the projection (VIP), and finally, 7) estimating the model parameters of predicting NP.

\section{The Partial least squares (PLS) regression:}

The PLS regression procedure is efficient and optimal for the criterion based on covariances. It is recommended in cases where the number of variables is high, The method used in this study (referred to by XLSTAT software as PLS1) corresponds to the case where there is only one dependent variable, which is net profit (NP) in our case. The idea of the PLS regression is to generate a set of components out of the studied independent variables so that they explain as well as possible the dependant variable (NP), and have the characteristic of producing a model that involves linear combinations of explanatory variables. The model can be used for projection of NP or for simulation.

\section{RESULTS AND DISCUSSION}

Our aim in the present work was to assemble together information on the cost of raising egg-type pullets obtained from a large size-operation for an extended period of production (1990-2005). The analysis of the available data would be used in projecting net profit.

\section{Summery statistics:}

Variability in cost variables is mainly attributable to management conditions (Farooq et al., 2001; Zahir-ud- Din et al., 2001), size of operation (Ames and Negmba, 1986; Kumar and Mahalati, 1998; Ascard et al.,1995), mortality rate (North, 2001; Kitsopanidis and Manes, 1991; Asghar et al., 2000; Zahir- ud -Din et 
al., 2001, Abdel-Aziz et al., 2008), and feed efficiency (Elwardany et al., 1998; Abdel-Aziz et al., 2008).

Table 1 shows the means and standard deviations of the six studied variables, the dependent variable (NP) and the five selected explanatory cost variables: OC, DC, $\mathrm{CP}, \mathrm{FC}$, and $\mathrm{VC}$. The highest mean value was that of FC, which was about (L.E 156182) per cycle, followed by the price of the purchased chicks (PC), which amounted to about L.E 78847 per cycle, representing about $46 \%$ and $23 \%$ of the total cost respectively. These results were supported by Abdel-Aziz et al. (2009); Farooq et al. (2002). Abdel-Aziz et al. (2009) reported values of $37 \%$ - $46 \%$ for $\mathrm{FC}$, and $16 \%-21 \%$ for $\mathrm{CP}$.

Table 1. Summery Statistics

\begin{tabular}{lccc}
\hline \multicolumn{1}{c}{ Variables } & Observations & $\begin{array}{c}\text { Mean } \\
\text { (LE) }\end{array}$ & $\begin{array}{c}\text { Standard } \\
\text { deviation (LE) }\end{array}$ \\
\hline Net Profit(NP) & 43 & 62873 & 42208 \\
Other Cost (OC) & 43 & 49342 & 38057 \\
Depreciation Cost (DC) & 43 & 31911 & 19881 \\
Chick Price (CP) & 43 & 78847 & 58280 \\
Feed Cost (FC) & 43 & 156182 & 133189 \\
Veterinary Cost (VC) & 43 & 21570 & 22754 \\
\hline
\end{tabular}

Cost of feed is the major input variable, accounting for up to $70 \%$ of the total poultry production cost (Qunaibet et al., 1992; Zahid,1994;Leeson and Summers , 1997; Farooq et al.,2002). The contribution of day-old chick price to the total cost in table-egg production farms was 4 to $5 \%$ (Zahid, 1994; Farooq et al., 2002) and $9 \%$ in broiler breeders' farms (Abdel-Aziz, 2003; Abdel-Aziz et al., 2007). Whereas, Vaccination and medication cost contribute a portion which ranged between 3 and 5 \% (Zahid, 1994; Farooq et al., 2002; Abdel-Aziz, et al., 2008).

The large estimates of the standard deviations for all means reflected the wide range of values. For example NP ranged from L.E 20396 to, L.E 179064, and FC ranged from L.E 241865 to L.E 521673. This may be due to the long period of data collection (1990-2005) and to the wide differences of flock size in the production cycles which ranged from 25700 to 79500 birds (CFLD, 2009).

\section{The correlation matrix}

The correlations between all the selected independent variables and between each of them and the dependent variable (NP) are given in Table 2.

All correlation coefficients (r), including those between NP and other variables were high (over 0.90 in most cases), and significantly different from zero ( $\mathrm{P}<5 \%$ ). The estimates ranged from 0.61 up to 0.96 . The lowest correlations were found between OC and each of the other variables.

The $\mathrm{R}^{2}$ values (Table 2) allows the visualization of the coefficients of determination of NP and the explanatory variables. With the exception of $\mathrm{R}^{2}$ between OC and NP $\left(\mathrm{R}^{2}=0.49\right)$, all other coefficients exceeded 0.81 . 
Table 2. Correlation matrix (Pearson): among all studied variables

\begin{tabular}{lllllll}
\hline \multicolumn{1}{c}{ Variables } & CP & FC & VC & OC & DC & NP* \\
\hline Chick Price (CP) & & 0.960 & 0.949 & 0.607 & 0.923 & 0.909 \\
Feed Cost (FC) & 0.921 & & 0.963 & 0.675 & 0.930 & 0.937 \\
Vet. Cost (VC) & 0.901 & 0.928 & & 0.764 & 0.935 & 0.929 \\
Other Cost (OC) & 0.368 & 0.456 & 0.584 & & 0.615 & 0.699 \\
Depreciation Cost (DC) & 0.851 & 0.865 & 0.875 & 0.378 & & 0.928 \\
Net Profit (NP) & 0.827 & 0.878 & 0.863 & 0.489 & 0.862 & \\
\hline
\end{tabular}

NB: Values above diagonal are correlation coefficients (r) and values below diagonal are coefficients of determination $\left(\mathrm{R}^{2}\right)$.

* The dependent (response) variable

All values of (r) are different from 0 at a significant level alpha $=0.05$

\section{The Model Building}

The idea of PLS regression is to generate a set of components (h) starting from a number of variables $(\mathrm{p})$ with $\mathrm{h}<\mathrm{p}$. The determination of the number of components to keep is based on a criterion that involves cross-validation, or set by the user. XLSTAT - PLS has automatically selected one component. In our case there was also only one dependent variable (NP).

The obtained component is built to explain as well as possible NP. The PLS regression eventually leads to a linear model for projection of NP.

\subsection{The Model quality}

Table 3 and the corresponding chart (Fig.2) allow to visualize the quality of the PLS regression as a function of the generated component.

Table 3. Model Quality

\begin{tabular}{lc}
\hline Index & Component \\
\hline $\mathbf{Q}^{2}$ Cum & 0.897 \\
$\mathbf{R}^{2} \mathbf{Y}$ Cum & 0.900 \\
$\mathbf{R}^{2} \mathbf{X}$ Cum & 0.872 \\
\hline
\end{tabular}

Table 3 displays the model quality indexes. The quality corresponds to the contribution of the component to the indexes. The $\mathrm{Q}^{2}$ cumulated index $\left(\mathrm{Q}^{2}\right.$ cum $)$ measures the global contribution of the component to the predictive quality of the model. The $\mathrm{Q}^{2}$ cum is 0.897 , indicating a high degree of stability of the model (ideally it should be close to 1 ).

The cumulated $R^{2} y$ cum and $R^{2} x$ cum indexes are measures of the explanatory power of the component for the dependent variable (NP), and the five explanatory variables, respectively. The values of these two indexes correspond to the sum of the coefficients of determination given below the diagonal of Table (2) for the dependent and the explanatory variables. The values of $R^{2} y$ cum and $R^{2} x$ cum are 0.90 and 0.872 , respectively which are very close to 1 . This indicates that the component generated by the PLS regression summarizes well both the dependent variable and the explanatory variables. Fig.1 displays the values of the indexes of the single component generated by the PLS regression. 


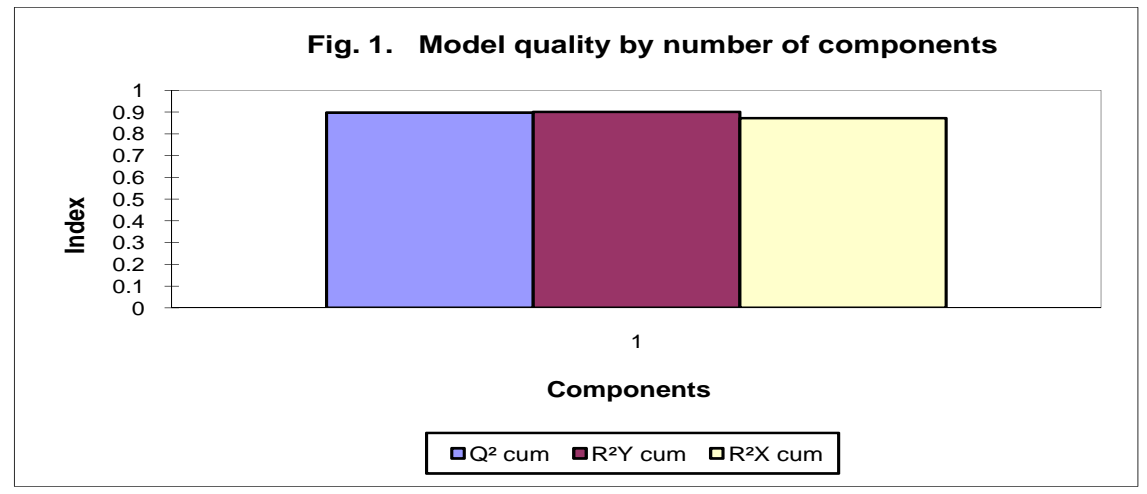

\subsection{The variable importance for projection (VIP)}

The VIPs are those variables that measure the importance of each of the explanatory variables for the building up of the components. This allows identifying which of the explanatory variables contribute more to the projection model.

Table 4. Variable Importance in the Projection (VIP)

\begin{tabular}{lcrcc}
\hline \multicolumn{1}{c}{ Variables } & VIP* $^{*}$ & $\begin{array}{r}\text { Standard } \\
\text { deviation }\end{array}$ & $\begin{array}{c}\text { Lower bound } \\
\mathbf{( 9 5 \% )}\end{array}$ & $\begin{array}{c}\text { Upper bound } \\
\mathbf{( 9 5 \% )}\end{array}$ \\
\hline Feed Cost (FC) & 1.059 & 0.005 & 1.049 & 1.068 \\
Vet. Cost (VC) & 1.049 & 0.005 & 1.040 & 1.058 \\
Depreciation Cost (DC) & 1.049 & 0.007 & 1.035 & 1.063 \\
Chick Price (CP) & 1.027 & 0.002 & 1.023 & 1.031 \\
Other Cost (OC) & 0.790 & 0.025 & 0.741 & 0.838 \\
\hline
\end{tabular}

* Listed in a descending order.

For the model of one component (Table 4), as it is the case in the present study, it can be seen that feed cost (FC) has the highest VIP value. Veterinary and DC are equally important for the projection. Two border lines for the VIP values are plotted to identify the variables that are highly influential, VIP $>1$, (Fig. 2). Four variables (FC, VC, DC, and CP) fell in this category. Only OC fell below 0.80 which marks the lower threshold of the moderately influential variables $(0.8<$ VIP $<1.0)$.

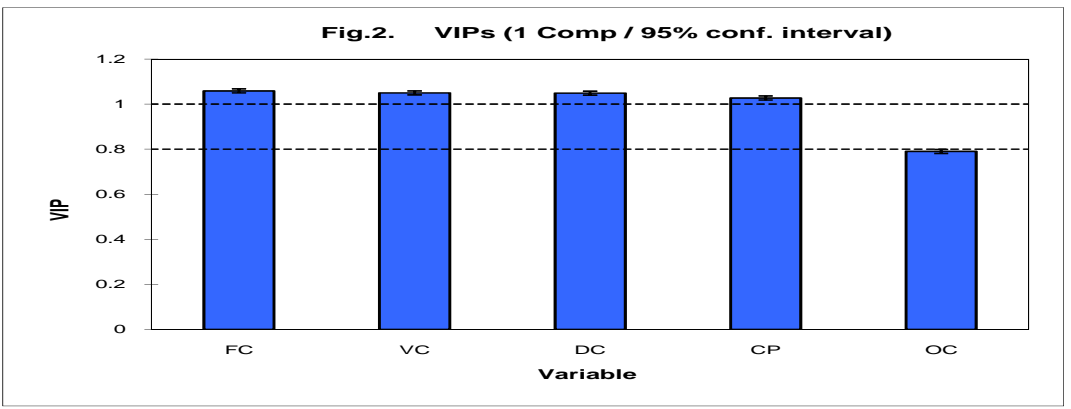




\subsection{The model parameters}

Table 5 contains the parameters (coefficients) of the model for NP projection. The Table is followed by the equation of the model. This equation can be used for prediction or for simulation purposes.

Table 5. Model parameters

\begin{tabular}{lc}
\hline \multicolumn{1}{c}{ Variable } & Net Profit (NP) \\
\hline Intercept & 8552.63 \\
Other Cost (OC) & 0.178 \\
Depreciation Cost (DC) & 0.452 \\
Chick Price (CP) & 0.151 \\
Feed Cost (FC) & 0.068 \\
Vet. Cost (VC) & 0.396 \\
\hline
\end{tabular}

The equation is displayed to facilitate the reuse of the model $\mathrm{NP}=8552.63+0.178 \times \mathrm{OC}+0.452 \times \mathrm{DC}+0.151 \times \mathrm{CP}+0.068 \times \mathrm{FC}+0.396 \times \mathrm{VC}$

\subsection{Goodness of fit for NP}

The goodness of fit statistics of the PLS regression model for NP are given in Table 6 .

Table 6. Goodness of fit statistics (Variable NP*)

\begin{tabular}{lc}
\hline Observations*** & 43 \\
\hline Sum of weights & 43 \\
Degrees of freedom (DF) & 41 \\
R square (R') & 0.900 \\
Std. deviation & 13532 \\
Mean square error (MSE) & 174603875 \\
Random Mean Square Error (RMSE) & 13214 \\
\hline
\end{tabular}

The analysis of the model shows that the model is well fitted $\left(\mathrm{R}^{2}=0.90\right)$. The Table also includes the number of observations (production cycles). The sum of the weights of the observations, the number of degrees of freedom which correspond to the error mean squares (MSE), and the root of the MSE (RMSE).

\section{CONCLUSION}

The partial least squares (PLS) regression procedure as described in the XLSTAT 20091.01 software is used successfully in developing a projection model for the net profit per cycle. Dependent (response) variable was accurately predicted from five budget independent (explanatory) variables with high accuracy $\left(\mathrm{R}^{2}=0.9\right)$. The analysis of the model shows that the model is well fitted and can be used for prediction or simulation purposes. The procedure can also handle more than one dependent variable and a large number of independent variables. 


\section{ACKNOWLEDGEMENT}

The authors wish to express their gratitude to Mr. Eng. Abdel Hameed Saied, Executive Director of the Central Fund for Livestock Development (CFLD) for making the data used in this study available. Also they like to thank the staff of AlNahda farm for their help in editing the on-farm information.

\section{REFERENCES}

Abdel-Aziz, Y.A., 2003. Evaluation of poultry production systems in Egypt. Ph.D. Thesis. Faculty of Agriculture. Cairo University.

Abdel-Aziz, Y.A., A.M. Atta and N.E. Gohar, 2007. Technical Features of the Commercial broiler Breeder System in Egypt. J. Anim. Prod., (2): 186-191.

Abdel-Aziz, Y.A., A.M. Atta and N.E. Gohar, 2008. Analysis of farm budgets of two commercial broiler breeder farms. J. Agric. Sci. Mansoura Univ., (10): 71857193.

Abdel-Aziz, Y.A., H.B.A. Gharib and M.A. Ibrahim, 2009. Net profit per bird in an egg- type pullets production farm as affected by Flock size. Unpublished data.

Ames, G.C. and L.M-Negmba. 1986. Poultry production in Zair. World Economic and Rural Sociology Abst., 28: 5189.

Ascard, K.E., Von. Wachenfelt and E. Von. Wachenfelt, 1995. Laying hens on the floor: inventory and review of experience. Special meddelande. Institutionen Jordbrukets. biosystem-och-Teknologi sverigos- lantbruksuniveritet. 216: 84 .

Asghar. A., M. Farooq, M.A. Main, Perveez and A. Khurshid, 2000. Economic of broiler production in Mardan Division. J. Rural Dev. And Admin., (17): 56- 64.

Central fund for Livestock Development in the Reclaimed Land (CFLD) 2009. Budget reports of El-Nahda farm.

Elwardany, A.M., B.T. Sherif, A.A. Enab, A.M. Adel-Sami, I.F. Mari and M.K. Metwally, 1998. Some performance traits and abdominal fat contents of three Egyptian indigenous Laying breeds. First international conference on animal production and health in semi-arid areas, El- Arish. September 1-3, 471-481.PP.

Farooq, M., M.A. Main and A. Asher, 2001. Factors affecting cost of production and net profit per broiler in the tropics, Journal of livestock research for Rural Development, (13): 11-16.

Farooq, M., M.A. Mina, F.R. Durrani, Zahoor- Ul-Haq and M. Syed, 2002. Standrizing limits for cost of production in commercial egg operation. International Journal of poultry science, (6): 179-184.

Hofstad, M.S., H. John Barnes, B.W. Calnek, W.M. Reid and H.W. Yoder, 1984. Diseases of poultry. Iowa state university press, Ames, Iowa, USA.

Kitsopanidis, G. and B. Manos, 1991. Evaluation of the degree of variation in profitability of poultry meat production according to certain factors. Epitheorese Zootenhinkes Epistemes. 14: 59- 71.

Kumar, V.P. and S. Mahalati, 1998. Cost analysis of Layer farm in South-west Madhya Pradesh. Indian Journal of poultry science, (33): 110-112

Leeson, S. and J.D. Summers, 1997. Commercial Poultry nutrition. University Books, P.O.Box 1326, GUELPH, Ontarios, Canada.

North, M.O., 2001. Layer Management. In Commercial Chicken Production Manual. The Avi. Publishing company. Inc. Westport. Connecticut. 
National Research Council, 1994. Nutrient Requirements of Poultry. $9^{\text {th }}$ Rev.edu. National Academy Press, Washington, D.C.

Qunaibet, M.H., E.A. Elwafa and M.M.Mansour, 1992. Improving the competitive status of Saudi broiler industry. J. King Saudi University, Agr. Sci. (4): 164-184.

XLSTAT, 2009. Statistical software for MS Excel- Statistics and data analysis with MS Excel Addinsoft 224 Centre Street, $3^{\text {rd }}$ Floor New York, NY 10013 USA.

Zahid, M.H.,1994. Economics of Layer production on commercial poultry farms in Urban Faisalabad. M.Sc. Thesis. Faculty of Agri. Eco. and Rural Social Sociology. Uni. Agr. Faisalabad.

Zahir-ud-din, M. Farooq, F.R. Durrani,N. Chand and J. Ahmed, 2001. Status of broiler produced in Swat, Pakistan, Journal of Livestock Research for Rural Development. (13): 3-6 
إستخدام طريقة الإنحدار الجزئي للحد الأدنى للمربعات للتنبؤ بصافي الربح من بداري إنتاج البيض ياسر أحمد عبدالعزيز، حسن بيومي علي غريب²، محمد عبد العزيز إبراهيم2

1- معهب بحوث الإتتاج الحيوانسي، وزارة الزراعه، الجيزه، مصر، 2- قسم الإنتاج الحيوانس، كلية الزراعة، جامعة القاهرة، الجيزة، مصر الاناج الجيران

جمعت البيانات المالية لعدد 43 دورة لإنتاج بداري إنتاج البيض اللو همان البني نفذت على مدار مدار 15 عامـا

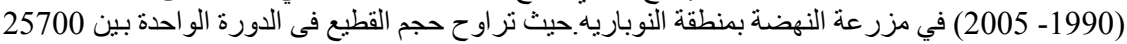

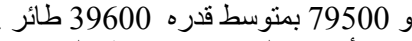

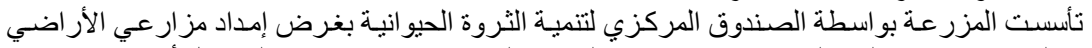

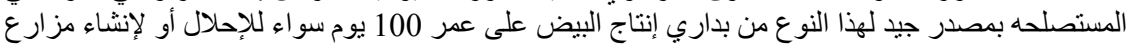
صغيرة جديدة.

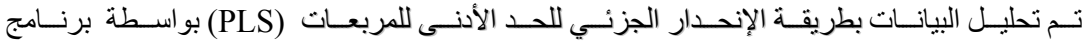

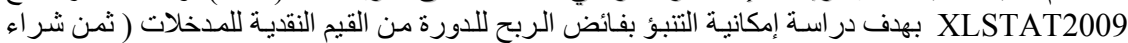

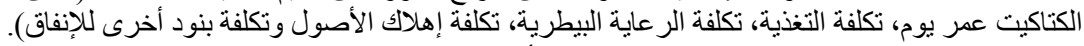

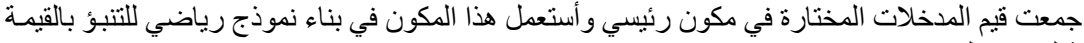

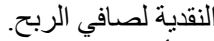

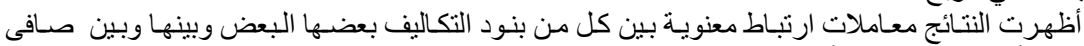

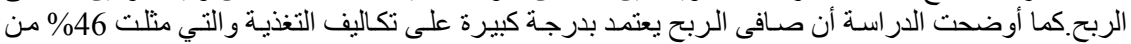

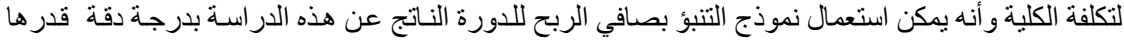

